\title{
APRENDENDO A CAMINHAR
}

\section{Glauciane Pinheiro Lima ${ }^{1}$}

Resumo: O presente texto trata do memorial sobre a trajetória escolar de Glauciane Pinheiro Lima, ex-integrante do Programa Conexões de Saberes. Tem como objetivo apresentar os passos percorridos desde o início da educação básica até a entrada à UFPA e quais os principais entraves de estudantes das comunidades populares adentrarem o ensino superior público. A memória foi usada como principal referência para construção do material. Em seus resultados, apresenta os esforços individual e coletivo para que de fato a educação seja uma questão de direito e não de privilégio de poucos.

\section{I-Primeiros Passos}

Meu nome é Glauciane Pinheiro Lima, nasci em Soure, uma cidadezinha ao leste da Ilha do Marajó, a qual, segundo dados do IBGE (2000) possui apenas vinte mil habitantes. Sou filha de Melckesedeque Lima e Edna Lúcia Pinheiro. Considero-me uma pessoa forte, uma legítima cabocla marajoara porque, desde que nasci, venho transpondo barreiras. Chegar à universidade foi uma destas barreiras, por que chegar aqui não foi tarefa fácil: nós sofremos muito, eu minha família, para que, pelo menos um filho, até o momento, conseguisse entrar na Universidade. Venho de família humilde, meu pai é funcionário público, minha mãe é dona de casa e vendedora autônoma. Tenho quatro irmãos: Gilson, Tatiane, Rodrigo e Tayane; sou a terceira filha na ordem de nascimento e a diferença de idade entre mim e minha irmã mais velha é de apenas um ano. Pelo fato de sermos uma família numerosa, com apenas um provedor assalariado, nossa situação financeira sempre foi difícil.

Nasci em 1984, ano em que o país passava por grandes transformações políticas e econômicas (época da reabertura política, de planos econômicos desastrosos), quando tudo se tornava difícil e, para os pobres, a situação era pior. Conosco não era diferente. Durante os primeiros anos de minha vida não tínhamos casa própria, morávamos, ora na casa da minha "vó" Chica, ora na casa da "vó" Nilma (já falecida) ou, ainda, em casa alugada. Nessa época só o papai trabalhava, ganhava apenas um salário mínimo cortando carne em um açougue. Nessa época, meus dois irmãos menores ainda não eram nascidos e não chegaram passar por tantas dificuldades.

Trabalhando muito, meu pai conseguiu comprar um terreno na periferia da cidade, no

\footnotetext{
${ }^{1}$ Acadêmica* do Curso de Letras - Habilitação em Língua Francesa no Campus Universitário do Marajó-Soure, e-mail: jemappellegal@yahoo.com.br

* atualizado pela última vez em 2008.
}

Revista PET Interdisciplinar e Programa Conexões /UFPA On-line. Ed. Especial - 2017, BELÉM/ PA - ISSN 2447-097X 
Bairro Novo, mas para eles não importava, queriam mesmo era ter sua casa própria. Nessa época eu tinha três anos e morávamos na casa da "vó Nilma',' minha avó paterna. Na mesma casa moravam minhas tias com seus filhos, portanto, brigas eram constantes, fato que motivou papai a fazer nossa casinha. Era uma casinha mesmo! Como papai não tinha condições de fazer uma casa melhor, ele construiu uma casinha simples de pau e taipa, coberta com palhas de inajá (palmeira comum na região), na qual moramos por cerca de 5 anos.

Depois, já com ajuda de minha mãe trabalhando como autônoma (vendendo produtos da Avon, roupas, perfumes, etc), conseguiram fazer, aos poucos, uma casa melhor em alvenaria, onde moramos até hoje. Mas para isso, eles trabalharam muito. Papai passava o dia inteiro fora, quase não o víamos, porque ele saía de madrugada para trabalhar no mercado e à tarde trabalhava novamente no matadouro municipal. Só o víamos à noite. Tudo isso para nós dar conforto; não nos dava luxo, mas sempre teve o suficiente para nos criar com dignidade, destacando sempre a educação como um dos itens mais importante em nossa casa.

Meus irmãos e eu sempre estudamos em escola pública, pois além de não haver escolas privadas em nossa cidade, não tínhamos condições financeiras para sustentar tal luxo. Comecei a estudar aos 4 anos de idade, no ano de 1989. Minha primeira escola foi uma escola municipal, chamada "Prof'.Antonia Tavares", no mesmo bairro que eu moro, bem próxima à casa de minha avó Chica (Francisca Pinheiro). Como em quase toda escola pública do município, lá também havia carências, dificuldades de toda ordem, eu, criança, acostumada a ter pouco, achava normal. Àquela época, estudavam duas turmas numa mesma sala (turmas multiseriadas), por isso, até hoje, não sei quem foi minha primeira professora. Achava tudo ótimo, afinal eu estudava com minha irmã mais velha que sempre me defendia, ou tentava defender, dos alunos (as) maiores, pois havia sempre um aluno que roubava o nosso lanche e nos batia. Digo que precisava ser defendida porque sempre fui muito tímida, quando criança tinha uma dificuldade muito grande em me relacionar com as pessoas (ainda tenho!). No entanto, um dia isto mudou, pois minha irmã precisou mudar de escola pelo fato de ter passado para uma série mais avançada. Como ela era adiantada uma série em relação a mim, ao final do ano, teve que mudar para outra escola e eu tive que aprender a me cuidar sozinha.

Em 1991, passei a estudar em outra escola, o "Colégio Stella Maris", uma escola de freiras da Ordem das Agostinianas, lá havia muito rigor e ordem, a exigência começava desde o uniforme composto por saia pregueada comprida (bem abaixo do joelho) e blusa (bata) branca, mais meias brancas e sapatos pretos (tipo boneca), até regras de comportamento como não gritar ou correr na escola e respeitar sobremaneira os professores e às "irmãs", pois qualquer

Revista PET Interdisciplinar e Programa Conexões /UFPA On-line. Ed. Especial - 2017, BELÉM/ PA - ISSN 2447-097X 
infração era motivo para castigo. Havia, ainda, o constrangimento sofrido ao ouvir as "gracinhas" dos alunos de outras escolas, que faziam piadas sobre o nosso uniforme, ou seja, para as meninas era bastante complicado. Porém, o mais importante, era o fato da educação ser de qualidade, bons professores e comprometimento das freiras com a educação. Até hoje é considerado um dos melhores colégios da cidade.

Foi nesta escola onde realizei parte de minha trajetória escolar. Foi onde aprendi a ler e escrever. Guardo ótimas lembranças dessa época, pois lá estudaram minha tia, minha irmã e algumas amigas de infância. Esta escola fica no centro da cidade, nós andávamos quase uma hora todo dia, ao sol quente do verão marajoara, ou sob a chuva - no inverno-, para chegarmos lá. Apesar da distancia tudo era divertido, eu era a menor da turma, tinha 6 anos, e lembro-me de quase tudo que nós fazíamos. Lembro, também, que meu irmão era proibido de ir conosco para a escola, porque sempre acontecia uma confusão quando ele estava por perto. No retorno era a mesma coisa, mas, quase sempre nós encontrávamos, um amigo da família que trabalhava na coleta de lixo que era, e ainda é, feita por carroças puxadas por búfalos, ele nos dava uma carona. Isto era muito divertido. Quando perdíamos a carona, tínhamos que nos preparar para correr, porque havia um senhor que colocava o cachorro atrás da gente, então precisávamos ser espertos e correr muito, como eu era a menor sempre ficava para trás.

Lembro, também, de todos os meus colegas dessa época e de todas as professoras: Marlene, Graça, Lucinha e Antônia são aquelas pelas quais eu tenho um carinho muito grande. Todas tiveram uma participação grande na minha formação educativa e humana, mas, apesar do carinho que eu sentia por elas, havia uma barreira entre elas e eu, a minha famosa timidez. Recordo-me de quando eu estava na $2^{\mathrm{a}}$ série e havia o dia da leitura, este era o pior dia da minha vida, pois, como eu sempre lia num tom muito baixo, ninguém me escutava e a professora me fazia ir até a frente ler. Mas tenho certeza que elas se recordam de mim, não porque eu fosse uma ótima aluna, mas porque sempre fui quietinha demais na sala de aula, servia de exemplo, porém não suportava esse título de "santinha". Também fui uma boa aluna, mas quase não conversava, tinha poucas amigas na classe. Hoje, quando recordamos desses bons tempos sempre é um bom motivo para risadas e "encarnação" porque eu era aluna mais chorona da turma. Já não bastava ser a "santinha", ganhei também o título, nada honroso, de "chorona".

A terceira série passou sem grandes incidentes, mas a quarta série foi o pior ano que cursei. Não consegui ter um bom rendimento, acabei repetindo o ano, decepcionei meus pais e algumas pessoas que gostam de mim. Vestibular nessa época nem chegava a ser uma utopia porque nem pensava mesmo em fazer vestibular. Era uma coisa que ficava um tanto distante da 
minha realidade, nem sabia direito o que era isso, apesar de meu pai sempre falar que o seu sonho era ver seus filhos formados. Até cheguei presenciar a felicidade de minha tia quando passou no curso de Turismo pela UEPA, tinha, à época, nove anos, mais ou menos, e não entendia direito o porquê de tanta felicidade. Estava em Belém, só lembro que foi uma festa que contagiava a todos. Enfim, repeti a série.

No ano seguinte fui entender, finalmente, qual o significado de ingressar numa universidade, alguns conhecidos tiveram essa felicidade, a esposa do meu tio conseguiu passar no vestibular para curso de História pela UFPA e, novamente, foi uma grande festa. A partir desse momento, eu comecei a entender o que significava ingressar numa universidade. Passei, então, a estudar por dois objetivos: ingressar na universidade e realizar o sonho do meu pai que era ver pelo menos um de seus filhos formados em nível superior. Passei a valorizar mais os estudos e ser mais responsável com minha educação formal.

Quando passei para a quinta série mudei de turno, passei estudar de manhã. Recordome bem dessa fase: estudava com pessoas excelentes das quais sou amiga até hoje, tenho boas recordações dos professores, também estudava com dois primos. Infelizmente uma deles já não está entre nós, o Augusto, sua vida foi interrompida muito cedo, nos deixando saudades e muitas lembranças boas. As séries subseqüentes foram bem mais tranqüilas e consegui aprovação em todas.

\section{II - Dando Passos mais Firmes e Seguros}

No de 2002 passei para o Ensino Médio e tive que mudar de escola depois de muito tempo estudado na mesma escola. Aí tive que me adequar a uma nova metodologia um tanto independente. Esta nova escola, à época, era a única no município que ofertava o Ensino Médio (Segundo Grau) e era bastante criticada pela desordem administrativa, falta de interesse dos professores, superlotação das salas de aula, pois havia, também, um sério problema relativo a grande demanda de alunos, fato que fazia com que, aqueles pais que tinham condições financeiras melhores, mandassem seus filhos para estudar em escolas de Belém.

Como minha família não podia fazer isto, tive que ir fazer meu Ensino Médio por lá mesmo. Ao contrário de outras pessoas, nunca critiquei nenhum professor, nem os responsáveis pela escola, até porque devia ser difícil administrar uma escola onde boa parte dos adolescentes só queria saber de "curtir" e namorar, ficando os estudos relegados para segundo plano. A maioria dos meus colegas queria apenas concluir o Ensino Médio, para eles isto já bastava. Para mim não, pois eu tinha um objetivo: a universidade. Mesmo porque acredito que através de um 
diploma universitário podemos alcançar um emprego melhor e, assim, proporcionar uma vida melhor para nós e para os nossos.

Isto é fato no Brasil, principalmente para quem faz parte da chamada classe baixa, só ascende socialmente aqueles que têm mais escolaridade. Para o pobre, as dificuldades são muito maiores, as barreiras são mais evidentes, enfrentamos problemas que vão desde a dificuldade de suprir as necessidades mais básicas, como comer e vestir, até sustentar financeiramente os estudos, bem como conseguir vagas numa escola pública que ofereça educação de qualidade, o conforto e a motivação para manter a vontade de estudar e prosseguir com sonhos e objetivos de crescimento pessoal, social e profissional: o meu era ingressar numa universidade.

Mesmo diante dos problemas da escola, sempre tive consciência do meu papel de aluna, costumava seguir o "ditado", não é a escola quem faz o aluno e sim o aluno quem faz a escola e, acredito também o professor. Tinha, e ainda tenho um grande respeito por todos os meus professores, respeito muito a profissão, apesar de querer seguir a carreira, julgo-me incapaz de conduzir uma classe cheia de alunos cada qual com personalidade e problemas diferentes, tanto é que quando eu fui me matricular no Ensino Médio, uma das opções era o Magistério, mas optei pelo ensino Regular.

No primeiro ano correu tudo bem, apesar dos problemas da fase de adaptação: novas disciplinas, novos professores, consegui passar de ano com bom rendimento. Costumava sempre passar em todas as disciplinas antes da última avaliação porque achava um incômodo ficar em recuperação. Tive esta experiência em anos anteriores, como já relatei.

No segundo ano tive certo problema e não tive o mesmo êxito da série anterior: fiquei em recuperação em Química. Confesso que não suportava a disciplina, mas tive mais um motivo: adoeci e fiquei mais de um mês sem assistir às aulas. Também não me preocupei, até porque precisava somente de 0,5 pontos para passar nesta disciplina, desta forma, me dediquei às outras disciplinas que julgava serem mais importante como Língua Portuguesa e Matemática. Fiz a última avaliação sem nenhuma preocupação. No dia do resultado a surpresa: havia tirado zero. Nunca havia tirado uma nota parecida em toda minha vida e, justamente, em Química a disciplina na qual bastava tirar 0,5 ponto para ser aprovada. Mas, fiz a recuperação e consegui passar para o último ano, estava mais próximo de fazer o vestibular.

No terceiro ano reencontrei umas amigas com as quais já havia estudado em séries anteriores. É muito importante para eu citar seus nomes porque todas elas fizeram parte desta trajetória, são elas: Joelma, Ariane, Raquel e a Silvana. Éramos inseparáveis. Os outros alunos diziam que fazíamos parte de uma "panelinha" porque quase sempre tirávamos as mesmas notas. 
Concluí esta série com êxito e me despedi do Ensino Médio. Era hora de dar passos mais largos e, talvez, maiores que as pernas.

\section{III - Aprendendo a correr, cair e levantar:}

Concluído o Ensino Médio, era hora de partir para a luta e encarar o Vestibular. Era o final do ano de 2004. Enfim chegou a hora: era o dia da inscrição para o vestibular. Mas, como sempre, nada é fácil para o estudante de origem popular. As dificuldades para o acesso à universidade pública começam desde o processo de inscrição e, aqui, o valor da taxa é muito alto, nem sempre o estudante mais pobre consegue se inscrever. Como dificilmente se consegue a isenção, fica muito complicado arranjar dinheiro para pagar a taxa de inscrição e deixa-se de estudar. Aliás, penso que é o processo de seleção dos isentos na UFPA é muito injusto.

Nesse ano me inscrevi para a isenção do processo seletivo seriado da UFPA, o PSS, mas não consegui ser isenta. Fiquei desmotivada e até um pouco desinteressada, tanto que fui saber da inscrição para o vestibular somente no último dia, porém meus pais não tinham dinheiro suficiente para que eu me inscrevesse, mas, como sempre deram um jeito para todos nós estudarmos, eles conseguiram arranjar o dinheiro para pagar a taxa de inscrição. Minha irmã mais velha já havia feito prova para o vestibular por duas vezes, entretanto, não conseguira a aprovação. Agora chegara a minha vez. Fui me inscrever só havia três cursos, optei por Letras com habilitação em Língua Francesa. Confesso que não era o curso dos meus sonhos, mas, mesmo assim, me inscrevi. Eu não estava confiante, meus pais tinham mais confiança em mim que eu própria, pensava que não havia estudado o bastante. Não fazia cursinho como os meus concorrentes, estudava no fundo do quintal de casa, sozinha. Mesmo assim consegui passar na primeira e na segunda fase do PSS, agora faltava apenas a última. Foi quando o meu tio Antônio, irmão de minha mãe, fez questão de pagar um cursinho para me auxiliar. Fiz a última prova e pensava que não iria conseguir

No dia do resultado quase não acreditava que meu nome estava entre os aprovados. Foi uma alegria enorme em minha família. Todos festejando: amigos, a família, todos felizes, afinal eu seria a primeira pessoa em minha família a ingressar na universidade. Naquele momento pensei, "tão pouco poderia transformar uma vida ou quem sabe uma sociedade".

$\mathrm{O}$ acesso ao ensino superior, um direito de todo cidadão, que era para ser um processo normal na vida escolar/acadêmica de um estudante/cidadão, como em outros países, no Brasil configuram-se num processo de sofrimentos, dificuldades e frustrações. Sofrimento para toda a família e para todos aqueles que nos amam. Isto sem lembrar aqueles que "ficam para traz", 
daquelas centenas/milhares de pessoas que sequer têm a oportunidade de acesso ao Ensino Básico ou daqueles que, mesmo se dedicando durante anos, não conseguem alcançar o tão sonhado curso superior. No meu curso, por exemplo, apenas vinte cinco conseguiram uma vaga das cinqüenta ofertadas para o PSS 2005. Questiono-me então: onde estão os colegas que, agora, poderiam estar aqui comigo? Porque lhes foi negado isto? Por isso agradeço muito a Deus por permitir que eu proporcionasse tamanha felicidade para meus pais e toda a minha família e também por permitir que agora eu possa estar refletindo sobre estas questões.

\section{IV - Um "salto" para Futuro:}

Iniciam-se , então, as aulas, todos estavam empolgados e eu, nem tanto. Pois não era o curso dos meus sonhos como mencionei. Sou "apaixonada" por arte, desejo conhecer o universo das expressões visuais. Mas também nem sabia o certo o que era o curso de Letras. Minha cunhada Darlinda se formara em Letras um ano antes de eu ingressar na Universidade, mas nunca me interessei em saber do que tratava o curso. Além disso, há certa resistência das pessoas em relação ao curso de Letras e às licenciaturas de modo geral, dá muito mais valor em profissões como Medicina ou Advocacia, e menos valor ao Magistério. Este acabou sendo um dos motivos para o meu descontentamento com o curso.

De tantas batalhas vencidas, começaria mais uma: enfrentar a tão temida universidade. Refiro-me desta maneira porque é tão difícil chegar até ela, principalmente para um estudante de origem popular, e a gente recebe tantas negativas, que acabamos por pensar assim. $\mathrm{Na}$ verdade, para mim, tudo parecia mesmo mais difícil.

Lembram do início de minha história, quando eu ressaltava a minha timidez, aquela que carrego desde criança. Pois agora tudo parecia ser ainda mais complicado já que eu necessitava me enunciar através da fala e pior ainda, num idioma estrangeiro diante do público, pois o curso exige esse tipo de exposição. Entrei na universidade sem ter a mínima noção de que o curso de Letras estuda, pesquisa e ensina o universo das linguagem escrita e falada, justamente, o que era o meu ponto fraco.

No começo pensei em desistir, mas conclui que seria fraqueza renunciar a um sonho na primeira dificuldade. Além disso, o curso não estuda somente a linguagem, estuda também a literatura, a arte e a cultura de outros povos. No meu caso, tudo gira em torno da língua francesa, o que me motivou continuar o curso. Agora, estou gostando muito da idéia de aprender uma língua estrangeira, de me tornar professora de francês. Meus colegas de curso são ótimos, nós sempre estamos nos ajudando nas horas difíceis.

Revista PET Interdisciplinar e Programa Conexões /UFPA On-line. Ed. Especial - 2017, BELÉM/ PA - ISSN 2447-097X 
Mas outro problema eu tinha que enfrentar, talvez, o, mas difícil entre os alunos universitário de origem popular, que é o problema financeiro. Moro numa cidade de vinte mil habitantes, onde há poucas opções de emprego: ou é atuando no comércio como atendente de lojas ou como funcionário público, mas isso depende de sua relação com os políticos da cidade. Então como manter os estudos, quando não se tem emprego?

Em casa só papai empregado, mesmo assim ganhando um salário mínimo. Minha mãe sempre ajudando, mas nem sempre é suficiente. Todos crescemos, a despesa agora era diferente, meus irmãos e eu sem trabalho/emprego. Muitas vezes ia para as aulas sem os materiais didáticos (textos, livros etc) pedidos pelos professores, prejudicando, assim, o meu desempenho acadêmico, principalmente por estudar uma língua estrangeira quando estudar sem livro é muito complicado. Meus pais fizeram, e fazem o possível para que não me faltar os devidos materiais, entretanto, isso permitia que faltasse para os meus irmãos o que fazia eu me sentir muito mal. Passei então ajudar para aliviar as despesas. Eu vendia, na sala de aula, bijuterias, roupas íntimas para os meus colegas, e a bolsa do Conexões de Saberes, apesar de alguns problemas operacionais e burocráticos no início, contribui sobremaneira para minha permanência na universidade.

Durante a minha estada na universidade aprendi bastante coisas, uma delas é que nada me faz inferior a nenhum outro aluno de qualquer outro curso, como os de Medicina ou de Direito, que são considerados curso de elite, porque a única diferença é apenas a escolha. Aprendi, também, a desenvolver uma reflexão crítica sobre os fatos que nos rodeiam, sobre questões como direitos do cidadão, sobre o meu engajamento como cidadã e agente de transformações sociais, políticas e econômicas no mundo, principalmente, depois que passei a fazer parte do Programa Conexões de Saberes, cujo objetivo é, justamente, promover estudos que viabilizem a garantia do ingresso e a permanência dos estudantes de origem popular, como eu, à universidade.

Hoje posso dizer verdadeiramente que sou abençoada, pois todas as minhas dificuldades estão sendo superadas, algumas já foram afinal: vitórias sem dificuldades não têm sentido. Meus amigos da turma de francês contribuíram bastante para a minha permanência no curso. Hoje estou no sétimo semestre do curso, estou gostando do curso, as dificuldades existirão sempre, mas estou pronta para enfrentá-las, afinal já venci batalhas maiores e piores que estas. 